\title{
Problems, struggles and some success with spinal cord injury in Zimbabwe
}

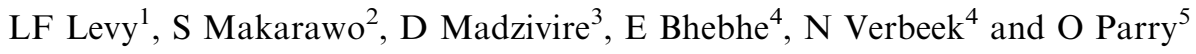 \\ ${ }^{1}$ Department of Surgery, Medical School, PO Box A178, Avondale, Harare; ${ }^{2}$ Parirenyatwa Hospital, PO Box \\ CY198, Causeway, Harare; ${ }^{3}$ Department of Rehabilitation Science, Medical School, PO Box A178, Avondale, \\ Harare; ${ }^{4}$ National Rehabilitation Centre, PO Box CY44, Causeway, Harare; ${ }^{5}$ Department of Physiology, University \\ of Zimbabwe, PO Box MP167, Harare, Zimbabwe
}

\begin{abstract}
Spinal cord injury is a common occurrence in Zimbabwe and carries with it a high morbidity and mortality. In the past almost all patients discharged from hospital were dead within a year. Reasons for this high mortality are presented. The establishment of the National Rehabilitation Centre has had a profound impact on the survival of these individuals as well as on improving their quality of life. The results of a retrospective survey on the mortality and life situation of individuals with spinal cord injuries sustained through trauma are presented. However major unresolved problems are inadequate housing, lack of financial support, practically no prospect of employment and depression compounded by boredom.
\end{abstract}

Keywords: spinal cord injury; morbidity; mortality; life situation; Zimbabwe

\section{Introduction}

The mortality and morbidity of spinal cord injury is very high throughout the Third World. A study undertaken by us in Zimbabwe in the early ' $60 \mathrm{~s}^{1}$ indicated that approximately $90 \%$ of quadriplegics and paraplegics died within 1 year of discharge from hospital into the community. Similar values were recorded in Nigeria by $\mathrm{Nwagu}^{2}$ in the late '70s. These figures are similar to those which were noted in Europe before the last world war. ${ }^{3}$ Nonetheless the prevalence of this disorder in Zimbabwe is high due to trauma, infection and neoplasm; and rehabilitation therefore presents serious problems.

The first section of the paper is a descriptive account of problems faced by health care professionals who treat and rehabilitate the spinal cord injured, and the means by which some of these problems have been surmounted. This account is based on more than 30 years work caring for such individuals. In the latter part of the article the results of a retrospective survey on a group of traumatically injured patients rehabilitated at the National Rehabilitation Centre will be presented.

\section{Early handling}

The first difficulty encountered concerns the handling of the patient before he reaches the neurosurgical unit. At present we have no control over this. In cases of trauma, the patient is almost invariably picked up by unskilled people, and frequently placed into inadequate

Correspondence: LF Levy transport for conveyance to hospital. Rarely does he reach our care in less than $24 \mathrm{~h}$ and sometimes several days may elapse. Non-traumatic cases are often kept for much longer periods at the initial hospital, either because the doctors may feel that they can get the condition to resolve, or simply because there is difficulty in finding the transport for a case that does not appear to be acute. Thus the condition may be aggravated by improper handling or the passage of time. A North American study ${ }^{4}$ suggested that in 1975 $40 \%$ of all spinal cord injuries did not survive to reach the acute hospital - we have no corresponding figures.

\section{Diagnosis}

The next problem concerns diagnosis. The history and plain X-rays will resolve many problems such as trauma and tuberculosis but others may require special tests which can take some time to perform. There have been occasions when it has been necessary to do a surgical procedure on a clinical basis alone rather than wait the long period for more accurate diagnosis. Naturally all of this militates against a successful outcome.

\section{Hospital care}

Immediately after admission to hospital, nursing problems become paramount. Decubitus ulcers, and urinary tract and chest infections kill many and delay rehabilitation endlessly. A study from Nigeria undertaken about 15 years ago showed that $25 \%$ of their traumatic paraplegia cases died during the hospitaliza- 
tion period. About $60 \%$ of them had decubitus ulcers and all had urinary tract infections. ${ }^{5}$ Of a group of traumatic paraplegics admitted to the National Rehabilitation Centre (in Zimbabwe) between 1988 and $19947 \%$ demised during the hospitalisation period from septicaemia as a result of decubitus ulcers. (Mortality figures from other institutions are unfortunately not available). We know that if a patient is turned regularly every $2 \mathrm{~h}$ and can be persuaded to sleep on the face, the chance of developing these sores is greatly reduced but many of them refuse to do it. In consequence such ulcers are a very common problem especially for the overweight, and an enormous amount of money and time is spent trying to heal what is preventable. A 'turning team' whose job it would be to go around any hospital turning all inert patients, would be of enormous benefit and save lives and money. Most patients need an indwelling catheter for a considerable period. This is partly because of the lack of staff to undertake intermittent catheterisation, and partly because of an almost total resistance by the patients to doing it for themselves. To our knowledge only two patients have willingly taken on this chore. Thus despite intensive bladder training exercises and close monitoring, many succumb to urinary tract infection; and decubitus ulcers and urinary sepsis remain the major causes of death. Respiratory problems in the acute phase of quadriplegia also claim their share of lives - and the patient with a high cervical lesion has virtually no chance of survival. (From a philosophical and humane stand point perhaps this may be the kindest thing - the Third World does not have the resources to provide any kind of a satisfactory life for such disabled people).

Longer term medical problems are muscle spasms, secondary contractures and ectopic calcifications. Intensive physiotherapy and drugs can hold the first two at bay in many cases, but where there are insufficient rehabilitation assistants and insufficient money to buy the necessary drugs they can present a very serious problem. Selective neurectomy, tenotomy or other surgical procedures can help but in severe cases where the patient has become markedly contracted we have found that mid-thigh amputation is the only solution for these unfortunate people. This is a terrible decision for staff and patient to make but there is no question that where it has been accepted and the weight of the fixed lower limbs is taken off the body, decubitus ulcers have healed easily, the patient can keep himself clean and he is more mobile. Those who have accepted this are happy (Figure 1). Ectopic calcification makes its appearance frequently despite physiotherapy and may progress relentlessly to grossly restricted movement.

Perhaps the biggest problem of all is the patient's mental attitude. The majority see themselves as totally useless and non-contributory; as unfortunately do many of their families also. In consequence most see only a blank wall in front of them as far as the future is concerned. Both sexes are terrified of desertion by their spouses. It can be very difficult to instill a positive attitude and a patient lying totally devoid of motivation may effectively raise his level of paralysis by the development of contracted elbows and frozen shoulders. It has been our misfortune to actually see patients deliberately lying on their bedsores in order to prevent them from healing and thus delay the dreaded moment of discharge from hospital - they know they are safe with us - but fear greatly what comes after.

\section{Rehabilitation}

In the first instance rehabilitation has to be started in his own ward by the doctor involved with spinal cord injury and by his own efforts he must slowly build up a team of concerned people. There will be many failures and much that is disheartening, however in Zimbabwe we have managed to make some progress. After many years of struggle the National Rehabilitation Centre (NRC) which is located near Harare was opened by the Ministry of Health in 1988. It contains 50 beds and extensive physiotherapy and occupational therapy and social welfare departments. In the grounds are rondavels which can accommodate the families of patients on a temporary basis. The families are

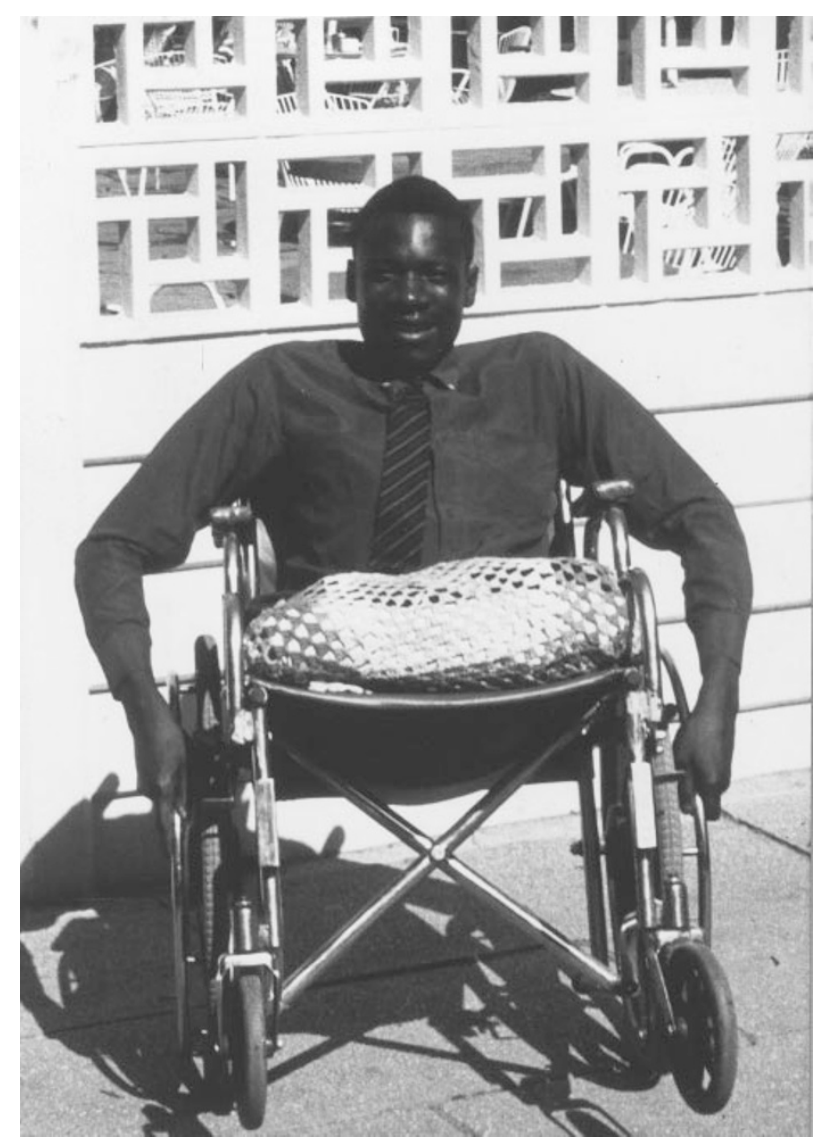

Figure 1 Healthy and happy this amputee holds a job as a hotel receptionist 
encouraged to spend a few days at the NRC learning how to care for their injured relatives once they are discharged. Unfortunately the NRC is very understaffed but nonetheless is doing magnificent work (Figure 2). The St Giles Rehabilitation Centre in Harare (a private charity) performs the same function for those with medical insurance or private means but faces all the same problems. For those fortunate enough to be admitted at either of these two institutions rehabilitation starts immediately.

The wheelchair problem has haunted us for a very long time. Wheelchairs produced abroad are designed for use on paved roads and are unsuitable for use on rural pathways and tracks, being neither sturdy enough to withstand the heavy usage to which they are subjected nor having wheels of adequate size to negotiate the rough surfaces of rural Zimbabwe. Furthermore, those which are made overseas are extremely expensive. We are now able to produce our own wheelchairs (Figure 3 ) in a disabled persons workshop and this has reduced costs immensely, but the problem of rural roads and small wheels remains.

It is very easy to lose sight of the patients

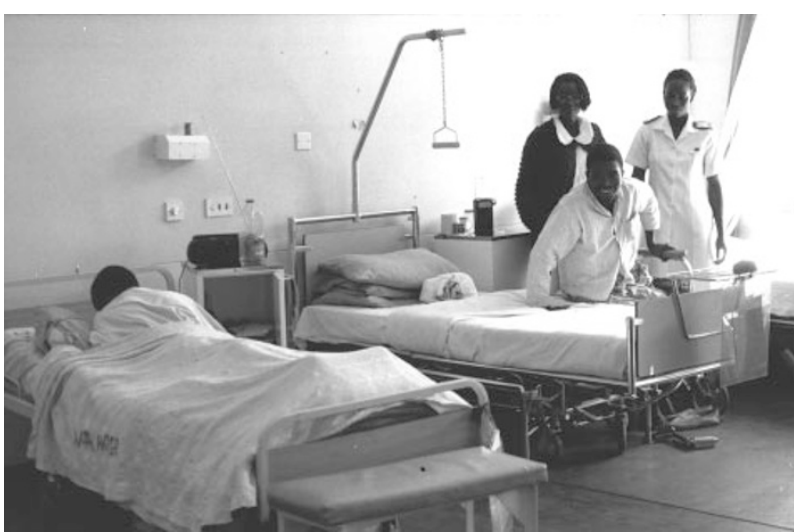

Figure 2 Ward staff assisting a patient learning transfers

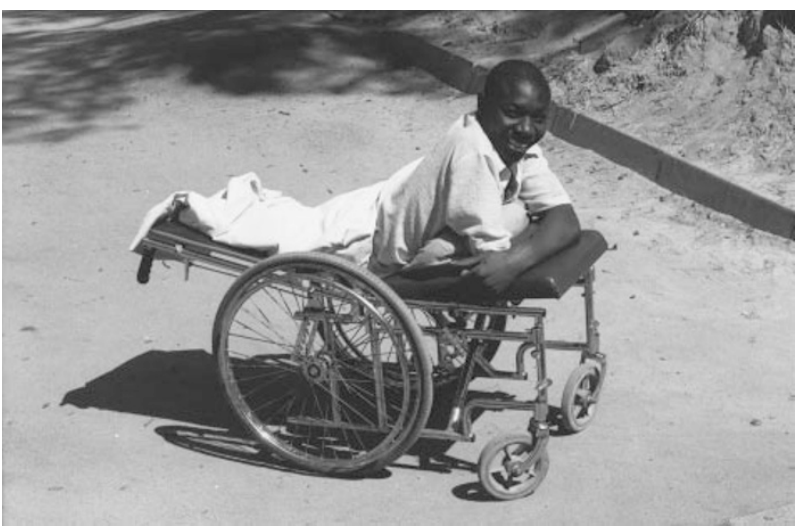

Figure 3 Wheelchair adapted for recumbent amputee particularly when they disappear into the country. A register of paraplegic persons has been developed with over 300 names thereon so that we can attempt to follow them and see they are well. However even this has its problems, a regular clerk and a budget is needed to maintain the register and we have not been successful in this respect.

\section{Special treatments}

Many paraplegic patients are severely angulated in the spine, particularly those associated with thoracolumbar fractures. It has recently been our policy to straighten such patients' spines and hold them in reduction by plating and fusion, irrespective of whether we thought that the spinal cord would or would not recover. We believe that the absence of a gibbus makes it more comfortable for the patient to sit in a wheelchair and also helps his respiratory function. Children have been seen with such gross kyphoscoliosis that the vital capacity has been reduced to a few hundred mls (Figure 4). Unfortunately we now consider it inadvisable to put metal into HIV positive patients and consequently less of this procedure is now being carried out.

The next problem is - can we do anything to improve function? It has been pointed out that the Third World cannot afford the equipment to make life tolerable for those with high cervical lesions. Therefore it is doubly important that any surgical procedure which can improve the arm and hand should be exploited to the maximum. The majority of our quadriplegic patients have injuries around the $\mathrm{C} 5-6$ and C6-7 level. They can abduct the shoulder, flex but not extend the elbow and usually extend the wrist. They can make very little active movement with the hand although they may be able to develop a 'key

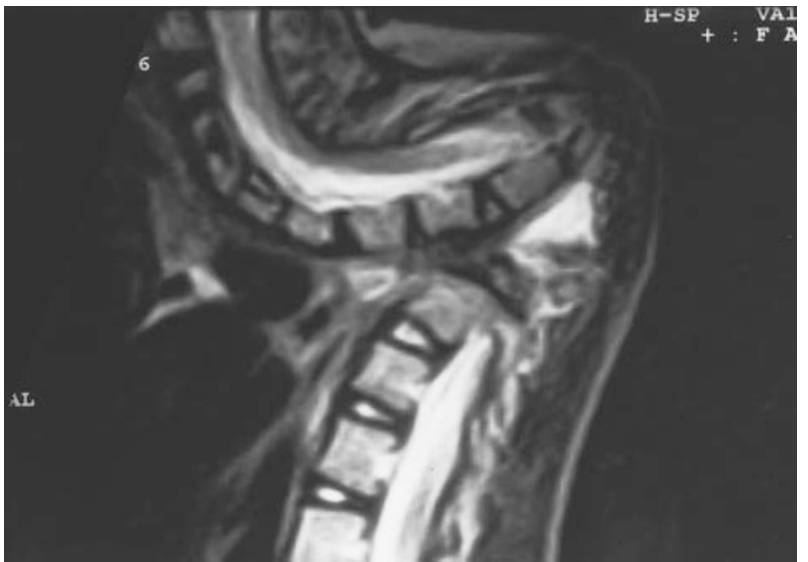

Figure 4 MRI scan of congenital kyphoscoliosis probably associated with neurofibromatosis in a 13-year-old girl. Owing to the scoliosis it is not possible to show all the affected vertebrae and the spinal cord in the same picture. (Courtesy of Dr N Jonker) 
grip' between thumb and finger by extending the wrist. The posterior one third of the deltoid muscle has been used to replace the triceps muscle and give extension of the elbow with good results and improved function ${ }^{6}$ but we have yet to advance into the hand since most are satisfied with the simple 'key grip'.

\section{Social and economic problems after discharge}

But the main and by far the greatest problem remains unsolved; when rehabilitation is complete where does the patient go and how, particularly the quadriplegic patient, is he/she going to be sustained? Recently we undertook a retrospective survey of patients who had spinal cord injury through trauma and who had been admitted to the National Rehabilitation Centre. Generally those who are rehabilitated at this institution are those who belong to the lower socioeconomic classes whose salaries disallow them to pay for private medical care and who do not have access to medical insurance. On discharge they tend to go to the rural or to the high density urban areas.

The objectives of the study were to determine whether the mortality and life situation of traumatic spinal cord injured patients had changed since the sixties and the inception of the NRC, and also to note the problems still facing these individuals once discharged into the community.

\section{Methods}

Patients were identified from the records of the NRC where information regarding their medical condition was obtained. A questionnaire was sent to each.

\section{Results}

Of the 432 patients who were rehabilitated at the NRC between 1988 and 1994, 136 suffered traumatic spinal cord injury; the overwhelming majority of which were males aged between 20 and 40 years. The predominant injury (Table 1) was fracture/dislocation of the vertebrae $(71 \%$ cervical - C5, C6 and C7; and 77\% thoracic or lumbar - mainly at T11, T12 or L1 level). $24 \%$ had no evidence of bony injury and in $12 \%$ the nature of the injury was indeterminate.

The majority of the injuries were sustained through road traffic accidents $(50 \%)$; others included assault $(11 \%)$, falling out of trees $(11 \%)$, off bicycles $(4 \%)$, out of scotch carts $(2 \%)$ and gunshot wounds $(4 \%)$. $18 \%$ were not recorded.

Of the 136 patients who were sent questionnaires 69 $(51 \%)$ were still alive at least 1 year following discharge, $34(25 \%)$ were known to have died and the remaining $33(24 \%)$ did not respond (Figure 5). Unfortunately we have no means of knowing if patients in this latter group are still alive. Of the 34 who demised, 10 died in the Rehabilitation Centre prior to discharge - mainly from septicaemia due to pressure sores. Of the remaining 24 who had spent time in the community and had subsequently died, two were known to be HIV positive and one died in a road traffic accident. The cause of death in the remaining 21 could not be ascertained. Two thirds of those who demised were quadriplegics (29\% of quadriplegics and $19 \%$ of paraplegics). Whether they were discharged into a rural or urban community appeared to have no bearing on survival. The mortality therefore lies between 25 and $49 \%$.

Of the 69 patients who were known to be still alive 63 answered the questionnaire adequately. They were divided on functional grounds into one of the following four categories: quadriplegics (cervical - A, ASIA impairment scale modified from Frankel; ${ }^{7}$ $n=20$ ); quadriparetics (cervical category $\mathrm{C}$ and $\mathrm{D}$, $n=7$ ); paraplegics (thoracic/lumbar category A, $n=17$ ) and paraparetics (thoracic/lumbar category $\mathrm{C}$ and $\mathrm{D}$, $n=16$ ). All four groups were included in the study. However three of the 63 patients were completely mobile (category E). Since the nature of the study was to investigate the life situation of patients still suffering from their injuries the three who were mobile were deemed to have recovered fully and the data from their questionnaires were discarded from the analyses.

\section{Analyses of the questionnaire}

Regarding their life situation, approximately 33\% of the individuals had pressure sores which were distributed throughout all four groups; surprisingly only $20 \%$ of the quadriplegics had pressure sores.

Table 1

\begin{tabular}{lcc}
\hline Nature of lesion & $\begin{array}{c}\text { Cervical } \\
(n=69)\end{array}$ & $\begin{array}{c}\text { Non-cervical } \\
(n=67)\end{array}$ \\
\hline \#/Dislocation & $49(71 \%)$ & $51(77 \%)$ \\
No bone injury & $12(17 \%)$ & $5(7 \%)$ \\
Others & $6(9 \%)$ & $5(7 \%)$ \\
Indeterminate & $2(3 \%)$ & $6(9 \%)$ \\
\hline
\end{tabular}

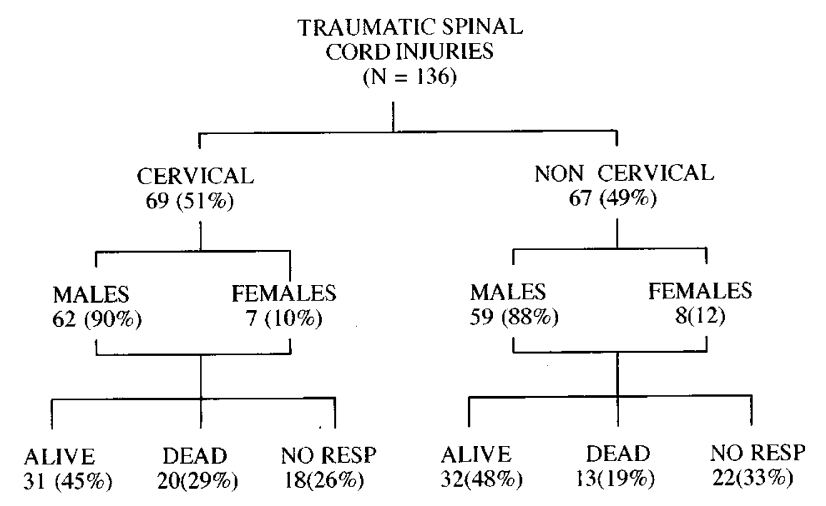

Figure 5 Flow chart showing the demographic details of the patients 
Bladder and bowel training were taught at the NRC and most of the patients were discharged with the belief by the staff that such training had been accomplished. However only $2 / 20 \quad(10 \%)$ of the quadriplegics claimed they had full control of the bladder; 12 of the remaining 18 used Paul's tubing and the situation relating to the remaining six was unclear. The majority of the quadriparetics (6/7) had full bladder control. Of the paraplegics $7 / 17 \quad(40 \%)$ claimed bladder control, 8/17 (47\%) used Paul's tubing and two had no control. All but one of the paraparetics had bladder control; the other practised self catheterization. Intermittent self catheterization was not reported as a means of control by any of the other patients. It was difficult to ascertain from the questionnaire answers whether or not patients had bowel control.

Pain was a prominent feature in the lives of many of these patients regardless of their functional groups. $77 \%$ complained of pain, although from the answers to their questionnaires the pain may not have been related to their injury. It was heartening to note that $78 \%$ had wheelchairs or appropriate aids for walking; $77 \%$ had someone to care for them whilst $7 / 17$ (41\%) paraplegics were taking care of themselves. A very small percentage $(13 \%)$ were employed including only one quadriplegic. Although over half $(53 \%)$ received either workers compensation or insurance because of the nature of their accident - this was often woefully inadequate. A third had no income whatsoever and relied on family and friends for financial support. When asked how they occupied their days the overwhelming majority replied that they sat in bed or in a chair and did 'nothing'. Few appeared to have access to books or any other recreational activities within their capabilities.

\section{Conclusions}

We like to think that the mortality of spinal cord injury in Zimbabwe has dropped since the early '60s. Half of the traumatically-injured patients who went through the National Rehabilitation Centre are surviving and are reasonably well. This has been achieved by better rehabilitation of the patients and by educating their families. Indeed families are encouraged to spend a few days at the Rehabilitation Centre learning to care for their disabled relatives (Figure 6). It seems that the incidence of pressure sores has decreased. However the number of patients lacking bladder control is still unacceptably high as is the prevalence of pain.

For those injured at work the National Social Security Authority has provided a pension, and in serious cases an allowance for a carer. This means that the family can spare someone from the task of food production and water collection to look after that person. Usually where there is financial assistance for the patient the survival chances are greater. Unfortunately many patients are not injured

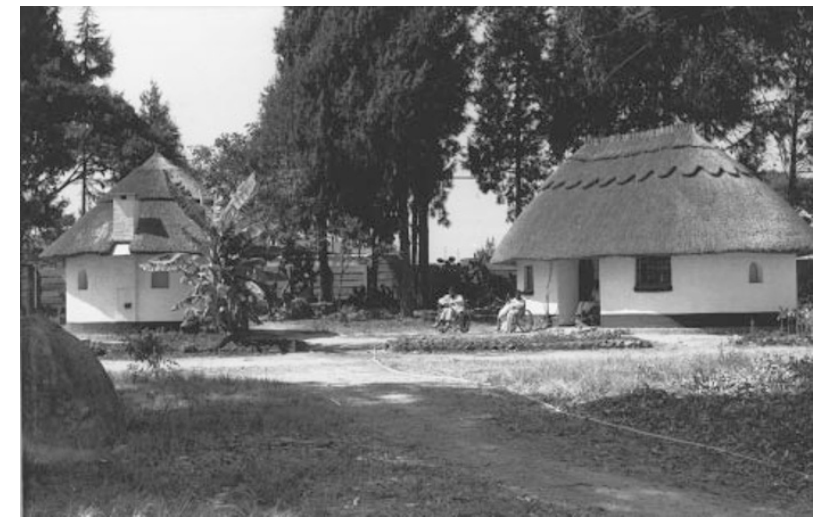

Figure 6 Rondavels used for family accommodation and teaching the activities of daily living

at work and compensation may not be available. These present the greatest problem because most have been labourers with no other skill on which they can rely. In these cases social welfare assistance is usually minimal or non existent. The Spinal Injuries Association provides a sheltered workshop for those resident in Harare in which new skills can be taught to those who are able to attend. Only a few are fortunate to benefit from this. The 'Harare Association for Paraplegics' has developed an urban centre as have the Cheshire Homes, where some paraplegics who have no other homes are living. This needs to be extended particularly so as regards the quadriplegics for whom there is no suitable home at present.

However other major problems still facing the spinal cord injured in Zimbabwe are boredom and lack of purpose. Unless we develop a very good financial and family support system and a strong personal drive we know we are virtually condemning that patient to death when we discharge them to outpatient care. That is the greatest problem of all.

\section{Acknowledgements}

The authors gratefully acknowledge the contribution made by the staff of the National Rehabilitation Centre, the St Giles Medical Rehabilitation Centre, The Cheshire Homes, the Waterfalls Paraplegic Home and the Spinal Injuries Association to the care of the spinal cord injured in Zimbabwe.

\section{References}

1 Levy LF. Follow up of 20 paraplegic and quadriplegic patients discharged from Harare Central Hospital. Unpublished Observations. 1965.

2 Nwuga VC. A follow up study of paraplegics and tetraplegics discharged from hospital. J Trop Med Hyg 1979; 82: 30-33.

3 Guttmann L. 'Spinal cord injuries. Comprehensive management and research' 2nd edn. Blackwell: Oxford 1976, p6. 
4 Gibson CJ. Overview of spinal cord injury. In Staas WE, Pitonno JF (eds) 'Physical Medicine and Rehabilitation Clinics of North America. Traumatic spinal cord injury' 1992; 3: 699-710.

5 Iwegbu CG. Traumatic paraplegia in Zaria, Nigeria: the case for a centre for injuries of the spine. Paraplegia 1983; 21: $81-85$.

6 Moberg E. Surgical treatment of absent single hand grip and elbow extension in quadriplegia. J Bone Joint Surg 1975; 51: 196.
7 Ditunno JF, Young W, Donovan WH, Creasey G. The International Standards Booklet for Neurological and Functional Classification of Spinal Cord Injury. Paraplegia 1994; 32: $70-80$. 